\title{
SOCIAL FACTORS AND PASHTO-ENGLISH CODESWITCHING: THE CASE OF ENGLISH AS EMBEDDED LANGUAGE IN KHYBER PAKHTUNKHWA, PAKISTAN
}

\author{
Arshad Ali Khan ${ }^{1 *}$, Naureen Nazir ${ }^{2}$, Abdul Hamid ${ }^{3}$, Neelam Nazir ${ }^{4}$
}

${ }^{1 *}$ Faculty member Department of Linguistics and Communications, Ph.D. and Associate Professor University of Management and Technology, Lahore, Pakistan; ${ }^{2}$ Research Associate, University of Management and Technology, Lahore, Pakistan; ${ }^{3}$ Assistant Professor Ph.D., Department of English and FLUniversity of Swat, Pakistan; ${ }^{4}$ Lecturer English, ELCUniversity of Central Punjab, Lahore, Pakistan.

Email: ${ }^{*}$ arshad.khan@umt.edu.pk, ${ }^{2}$ naureen.nazir@umt.edu.pk, ${ }^{3}$ abdulhamid@ uswat.edu.pk, ${ }^{4}$ neelam.nazir@ucp.edu.pk Article History: Received on $15^{\text {th }}$ March 2021, Revised on $29^{\text {th }}$ June 2021, Published on $30^{\text {th }}$ June 2021

\section{Abstract}

Purpose of the Study: The present research investigates the use of English codeswitching about the social factors which influence the use of English in the Pashto language. First, the focus of the study lies on the social factors e.g., style, interlocutors, topic, social distance, social status, and identity, etc., and their influence on English codeswitching in the Pashto language.

Methodology of the study: The data was collected with the help of a questionnaire consist of $13^{\text {th }}$ statements. The data collected were further analyzed with the help of quantitative and qualitative methods employing descriptive analysis, SPSS 15, and the percentage method.

Main Findings: The dominant pattern of codeswitching was insertion with nouns the most frequent codeswitching item. The study indicates that education is the key factor that influences English codeswitching and it also shows that Pashto is the dominant language of communication and is used as a symbol of solidarity and social marker in the Pashto speech community.

Application of the study: The researcher can extend this study of codeswitching to a different contact setting such Pashto-Urdu and Pashto-Punjabi. The density of bilingualism is expected to give different types of codeswitching patterns.

Novelty/Originality of this study: This study is the pioneer study that focused on the effect of social factors on the selection of language in bilingual settings.

Keywords: Social Factors, Codeswitching, Bilingualism, Embedded Language, Pashto-English.

\section{INTRODUCTION}

In sociolinguistics, bilingualism or language contact is a widely observed phenomenon in all the speech communities of the world. The language contact phenomenon includes interference, borrowing, convergence, pidginization, and codeswitching. Many studies have explored the nature of freedom of alternation between two distinct linguistic varieties (Azuma, 1997; Backus, 1998). Scholars seek to find structural constraints on code-switching and codeswitching to describe with accuracy what exactly occurs and why it occurs in this manner (Joshi, 1985; Bock, 1989; Romaine, 1989). They researched to discover if sociolinguistic factors influence the outcome of linguistic structures which are produced by the speakers (Gumperz, 1976; Heller, 1988; Hebert, 1992). In a society, different forces are always at work to influence the role of language in a certain domain (Fishman, 1972) setting, topic, and interlocutor. Such forces of society are known as social factors. Social factors are the driving force that determines the use of language at the right place and at right time. This quality of using language appropriately is called communicative competence. Communicative competence (Hymes; 1972) means the knowledge of social norms within society and its implication.

The study of the alternate use of two or more languages in the conversation has developed in two distinct but related directions: Structural and Sociolinguistic. The structural approach to codeswitching is primarily concerned with its grammatical aspects. On the other hand, the sociolinguistic approach sees codeswitching as a phenomenon influenced by social factors e.g., style, prestige, education, and appropriateness, etc.

A model operating within the confines of the Matrix Language Frame Model (Myers-Scotton, 1993), the Markedness Model (MM), is often used to describe the motivations behind codeswitching based on social situation (Myers 1998). The model attributes choices made by various social actors in their interactions with others, apropos of choice of language, dialect, style, or register and if the communication is a directive or a refusal, to the effect that they want to generate amongst their audience. This choice is not a reflection of the membership of the speaker in a certain social group, but is rather more reflective of what the speakers perceive will influence their listeners to meet a certain end. In MM, very often the goal of social interactions is to maximize benefit and reduce loss, thus social actors will adopt certain styles of speaking which may or may not achieve codeswitching to achieve those ends. The model itself suggests that in every social interaction, there exists a set of rules and obligations (RO) that governs how the interaction progresses (Myers 1998). Thus, every social situation has a normative model or unmarked choice that suggests how the interaction 
will proceed. This normative model is influenced by social factors, many of which have been researched in this paper. An actor thus chooses to either follow the unmarked choice or decides to reject the normative model and establish a new RO by making a marked choice through code-switching. Codeswitching then changes the state of the social interaction (Myers 1998). While MM applies to all levels of language, this research will confine itself to the code-switching dimension.

Linguistic behavior expresses complex social meanings. A study of codeswitching enhances our understanding of the relationship between language use and individual values, communicative strategies, and functions within particular sociocultural contexts (Auer, 1998; Jacobson, 1998; Myer-Scotton, 1993b). Blom and Gumperz (1972) observed that while greetings and inquiries about family affairs took in Ranamal, conversations about the business transaction occurred in the standard dialect. Blom and Gumperz also introduced three types of social constraints the presumably affect the code choices of speakers: 1) setting, 2) social situation, and 3) social event. According to these scholars, "some of the functions of codeswitching are intra-group identity", (Gumperz, 1982); "poetic creativity", (Kachru, 1989), and "the expression of modernization", (Kamwangamalu, 1989).

To know the role of social factors that influences codeswitching in a particular speech community, it is requisite to know the type of bilingualism in that society. The research work of Fishman (1972) indicates that there are three main social factors the influence the codeswitching i.e nature of interaction taking place in certain settings, with certain participants, and on certain topics. Baker (2001) states that if learners are acquiring a second language by choice by enrolling in pertinent ESL classrooms, then this is known as elective bilingualism. In Khyber Pakhtunkhwa, English is being taught as a second language and learners choose to learn this language due to academic purposes mostly. In such societies, L1 always has the dominant role and it is used as a language of communication in the community. Khan $(2014,2018,2020)$ has only focused on the structural dimension of codeswitching. This study is much important as English is the official language of Pakistan and many English words are indigenized with the help of phonological and morphological integration (Khan, 2016). The type of bilingualism that is observed in the KP of the Pashto speech community is selective bilingualism and that's why the density of bilingualism can only allow the patterns of insertion (Khan, 2014).

The following examples (1-2) show the Patterns of insertion in Pashto-English codeswitching data taken from khan (2014). The two verbs 'start' and 'play' in the BCV are bare verbs conjugated with the light verb kaw 'do' or 'make', which may carry a person and aspectual markers.

\section{Pashto-English Codeswitching (Khan, 2014)}

che da de format] ba sanga [start kaw -o]]

that. COMP of this format CL.FUT how start does.PRS.IPFV-1PL

'... that how we will start this format'

2. Pashto-English Codeswitching (Khan, 2014)

media [[negative role] hu play kaw -i]

Media negative role indeed play do.PRS.IPFV -3

'Media indeed play a negative role.'

The objective of this current study is to explore the influence of different social factors on English codeswitching in the Pashto speech community of Khyber Pakhtunkhwa (Pakistan). Through this study, the researcher aims to explore the relationship between codeswitching and social factors. This research also intends to discuss the role of social factors e.g., education, style, interlocutor, topic, context, prestige, status, and social distance, etc. in influencing English codeswitching (CM) in the Pashto language. The research question that is going to be explored in the present research is: Q1. What are the dominant social factors which influence the use of Pashto-English codeswitching?

\section{LITERATURE REVIEW}

The phenomenon of language contact has given birth to various phenomena, which include interference, borrowing, convergence, pidginization, and code-switching. The alternative use of two languages by bilinguals has evoked the interest of many linguists and has been studied from a variety of perspectives. As Milroy and Muysken (1995; pp. 1-2) note, the increasing use of international languages stimulated by modernization and globalization, the phenomena of language revival, and economically motivated migration of people have led to widespread bilingualism in the modern world. The studies of code-switching can be divided into three broad fields; sociolinguistics, psycholinguistic and grammatical constraints. In this work, different theories regarding code-switching as a social phenomenon have been analyzed. Code-switching has been investigated from various perspectives grammatical and social dimensions. A lot of work has been done based on grammatical constraints on code-switching. Auer (1984) warns "Grammatical restrictions on code-switching are but necessary conditions" (2); they are not sufficient to describe the reason for or effect of a particular switch. Such structural approaches failed to answer the basic questions of why switching occurs.

In this perspective over the last century, linguists have geared their research closer to the field of social inquiry. They broadened their research to the sphere of human behavior. In 1929, Edward Sapir urged linguists to "become aware of what their science may mean for the interpretation of human conduct in general" (1929:207). He further suggested to 
linguists that language should be studied within its broader social setting. With the development of sociolinguistics and psycholinguistics for some linguists, social interaction and human cognition were as important as the form and structure itself.

American linguist Chomsky (1957) came with his linguistic theory primarily concerned with an ideal speaker-listener, in a perfectly homogeneous speech community. His theory was a real deviation from the notion of socially engaged linguistics. In response to Chomsky's linguistic theory American Anthropologist, Hymes (1964) put forward his theory about communicative competence. He stressed socially integrated linguistic approaches to the study of language. He and other researchers also devised that linguistics should not be studied in isolation. According to Labov (1966), the definition of speech community language is the norm and should be studied concerning the social setting. Language is not an isolated entity; it is the result of the perception and attitude of the speech community.

Fishman (1967) developed Ferguson's (1959) concept and introduced the framework of domain analyses. In his work, language choices are constrained by a 'domain' consisting of topics, interlocutors, and settings. His work contributed to the notion of 'who speaks what language to whom and when. In Fishman's $(1965,1972)$ macro-level approach, he explained the relationship of language used in association to its social settings. In multilingual communities, multiple settings are there in the workplace e.g., formal, informal, local and official, etc. and through his, work Fishman associated different switching with different settings. He also explained the importance of the role of the topic in conversations. If two individuals speak in language $\mathrm{x}$ and never switch to language $\mathrm{y}$, it is only because the topic has no relation with language y, it means language or code-choices are also topic oriented. He shows the relationship of certain codes with certain topics.

This claim of correlation between activity and code choices is also supported by Gibbon's (1987) findings in his study on the code choices of a group of university students in Hong Kong. He found three types of language associated with different activities, the use of pure Cantonese, Mix (Cantonese-English code-mix), and pure English, etc. is associated with a specific domain. For example, pure Cantonese is usually used in the family domain among family members while MIX is usually used by university students to discuss school life.

Fishman's model has been criticized for being too general and does not tell anything about the individual verbal repertoire. It is only limited to situational switching and sheds no light on the switching taking place in face-to-face interaction. This tension between macro and micro-level in the study of language contact has aroused much fuss in the world of sociolinguistics. Much has been written about the social aspect of code-choice. The work of Blom and Gumperz (1972) is of great influence in code-switching research.

Gumperz (1958) has done extensive work on different dialects and their function in the social setting in India. There he found three levels - village dialects, regional dialects, and standard Hindi, each of which is associated with different social functions. The inspiration and source of his idea that linguistic form is affected by setting and participants as well as the topic are taken from Ervin-Tripp (1964). In her study, she finds that correlations exist between language choices and discourse content. Blom and Gumperz's (2000) work focused on individual verbal repertoire and found out about two distinct dialects Bokmal and local Ranamal while studying verbal behavior in multiple social settings in Norway. They identified different participants, settings, and topics as constraints that influence the choice in the verbal repertoire.

Gumperz (1982) analyzed several speech communities and explored six code-switching functions that are taking place during social situations. The suggested six code-switching functions that are similar to the contextualization cues are: quotation marking, addressee specification, interjection, reiteration, message qualification, and "personalization versus objectivization". Like contextualization cues which have been defined as "any feature of linguistic form that contributed to the signaling of contextual presupposition" (Gumperz 1982,p. 131) language alternation may also provide a means for speakers to signal how utterances are to be interpreted.

In $(1993,1993 b)$ Myers- Scotton incorporated micro-and macro perspectives into the code-switching research. She said that code-choice embodies the norms of society at large and understanding code choices is requisite. As each language in a society is associated with particular social roles. Myers-Scotton argued that when the participants are using certain codes, they not only show their understanding of the current situation but also the assigned role of the codes in a particular context. If they fail to understand the social meanings of the available codes then certainly there will be a failure in communication. She also proposed a negotiation principle, and three maxims i.e., unmarked choice maxim directs, marked choice maxim directs, exploratory choice maxim directs. Her work was criticized by Blommaert (1994) and Auer (1998) for being too much relying on external knowledge in a conversation, that speakers have no role of their own.

In the $20^{\text {th }}$ century, researchers and scholars have followed the footprints of pioneers in the study of language imbibed in culture and society. Bucholtz and Hall (2005) also integrated their work on language and identity as what they call "Sociocultural linguistics". Ho, J.W.Y. (2007) researched code-choice and codeswitching in Hong Kong and investigated the role of codeswitching patterns in different situations and settings. The focus of the research was to examine the linguistic form of the Cantonese-English mix and explore its socio-cultural meanings. Through his research, he proved that the codeswitching pattern is not spontaneous it is constrained by social factors like education. Khan (2014) research on codeswitching shows that if codeswitching happens between L1 and L2 (in the case of this study it 
was English and Phasto Language)the insertion remains the dominant pattern. Through study, it was found out that embedded language noun is the most prevalent switched element in the morphosyntax frame of Matrix Language. Khan $(2011,2014,2018,2018, \& 2020)$ has focused on the grammatical aspects of Pashto-English codeswitching. The studies of Khan (2014) are about the strategies of incorporation of English nouns and verbs in the Pashto language. Khan (2018) focused on the morphosyntax aspects of Pashto-English codeswitching based on the constraints proposed by the MyersScotton (1993 \& 2002) Matrix Language Frame model. The pattern of insertion was the dominant pattern of PashtoEnglish codeswitching.

In the light of the above review on different researches, it has been proved that language has multiple functions which are influenced by different social factors. To know the influence of social factors on codeswitching, the present study follows the framework set by Ho, J.W.Y. (2007) in his study on linguistic forms and socio-cultural meanings.

\section{RESEARCH METHODOLOGY}

This study has employed a quantitative approach to investigate the social factors that influence English codeswitching in the Phasto language. The epistemological approach to the study involved a deductive approach of moving from a broad generalization to a specific observation. The attempt was to determine how well existing literature and research stood in the context of a Pashto-speaking community in Pakistan. The approach was quantitative to ensure the reliability of the findings and replicability of the research method itself. The population of this study was all the students of private and government educational institutions of KPK. Their education ranged from secondary to postgraduate or its equivalent and their ages were between 18-36. The ethnic background of the respondents was Pashto and they were born and grown up in the same culture of Khyber Pakhtunkhwa (KP). All the speakers were bilingual in Pashto/English because of the ESL (English as a second language) classroom. They were also competent in the English language because of their education. To choose subjects for the study, the method of availability sampling was used so that participants could have been found easily. While collecting the data, it was ensured that ethical considerations were taken into account. The names of participants and the names of their educational institutions have not been disclosed and hence tagged as I1, I2, I3, and others. This study consisted of 125 participants among which 47 are male, 78 are female.

Table 1: Percentage of various demographics of participants

\begin{tabular}{lllll}
\hline & I1 & I2 & $\mathbf{1 3}$ & Others \\
\hline Gender & & & & \\
\hline $\mathrm{M}$ & 35.89 & 32.05 & 21.79 & 10.25 \\
\hline $\mathrm{F}$ & 36.17 & 40.42 & 17.02 & 6.38 \\
\hline Age & & & & \\
\hline $18-27$ & 9.6 & 5.6 & 8.8 & 3.2 \\
\hline $28-36$ & 16 & 12 & 4.8 & 1.6 \\
\hline $37-45$ & 12 & 14.4 & 9.6 & 2.4 \\
\hline Education & & & & \\
\hline Secondary & 6.4 & 5.6 & 4 & 0.8 \\
\hline Intermediate & 10.4 & 16 & 6.4 & 1.6 \\
\hline University & 23.2 & 16.8 & 7.2 & 2.4 \\
\hline
\end{tabular}

Table 1 shows the percentage of various demographics of participants. It contains the information on three sections i.e., gender, age, education of the participants.

A self-assessment questionnaire was developed which consisted of thirteen statements regarding social factors and each statement was accompanied by a three closed-ended Likert Scale. This study consisted of 125 participants among which 47 are male, 77 are female teachers and 1 choose not to disclose identity. This questionnaire aimed to infer the influence of social factors on English codeswitching in the Pashto language from the participants. While collecting the data, it was ensured that ethical considerations were taken into account. The names of participants and the names of their universities have not been disclosed. To investigate the influence of social factors on English CMin the Pashto language, the data was analyzed with the help of the SPSS 15 database and descriptive statistics for each statement were created according to the percentage. There are some drawbacks to the methods employed. Availability sampling is not a method that enables reliability in research and this defeats the purpose of adopting a quantitative, deductive approach to this research. However, due to cost and time constraints, the researcher had no other alternative.

\section{FINDINGS AND DISCUSSION}

To analyze data statistically, the SPSS software version 15 has been used. All the results have been discussed here in light of previous research and the research questions. The main focus of this study is on determining the influence of social factors on English CM in the Pashto language. 


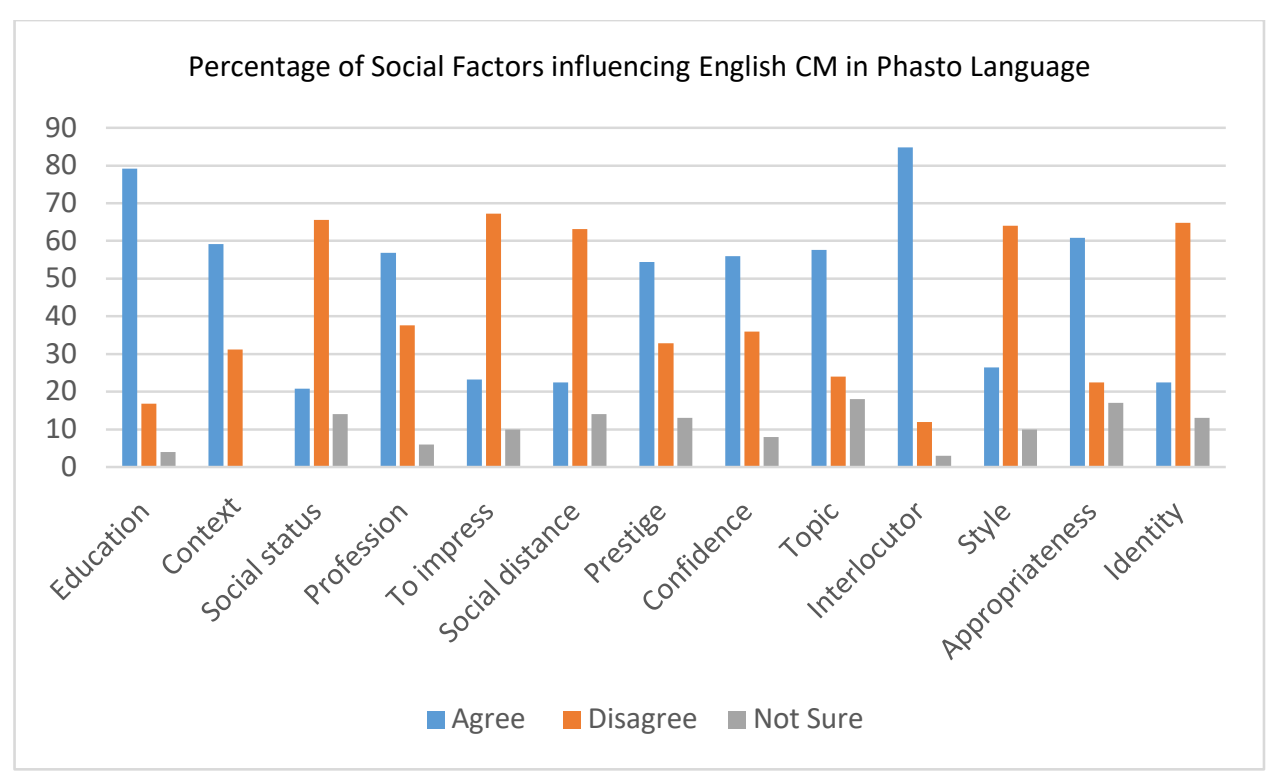

Figure 1: Percentage of Social Factors influencing English CM in the Phasto Language

\section{Source: Author}

Figure 1 illustrates the percentage of social factors influencing English CM in Pashto Language and shows which variable has the highest ratio among them.

\section{Education as a social factor and its influence on English CM}

The table/Figure (1) shows the results of the first statement question 'Education as a social factor, it is shown that $79.20 \%$ agreed $16.80 \%$ disagreed and $4 \%$ were not sure that whether education as a social factor influences their English codeswitching in Pashto language or not. This higher percentage suggests that education is a key factor influencing English codeswitching in the Pashto language. In Pakistan, English is considered the language of higher class, educated people and a source of instrumental gains. English is associated with white-collar jobs, especially in multinational companies, UNO projects, and renowned NGOs, etc. Therefore to make room for oneself in the economic market one must know the English language. This response to education as a social factor shows that education is highly associated with proficiency in the English language. In the context of MM, the unmarked choice for a person whose education is entwined with his social makeup may be to code-switch without making a marked choice to do so. However, in a hypothetical situation, if a social actor consciously wishes to demonstrate that he is educated, he may make the marked choice to reject the normative model which involves speaking in Pashto, and switch to English to influence the addressee's perception. With almost $80 \%$ of respondents agreeing that they use English because they are educated, it can be hypothesized that many of their interactions involve a marked choice to codeswitch to English.

\section{Context as a social factor and its influence on English CM}

Results (Table/Figure 1) show that 59.20\% agreed $31.20 \%$ disagreed. The outcome illustrates that English CM in the Pashto language is highly influenced by the social setting, formal or informal, official or local. In most private companies, private schools, and colleges English codeswitching is taking place during office work, during the classroom, with the boss, or with the client. The code-choice embodies the norms of society at large (Myer-Scotton 1987). Duranti (1992) in his study of Samoan 'respect vocabulary', has shown how detailed micro-analysis, relating terms and expressions to their use by particular speakers, in particular settings, to particular effect can provide a fuller understanding of the sociolinguistic phenomenon.

Thus, in terms of MM, if the unmarked choice is not clear, social actors make a marked choice to try and understand the RO of the interaction by code-switching. The response they receive then clarifies the context of the social situation to them, and they then may continue to code-switch or desist. If the unmarked choice is clear, it can be seen that nearly $60 \%$ of respondents would code-switch if the unmarked choice calls for it.

\section{Social status as a social factor and its influence on English CM}

The third social factor that has been analyzed is 'Social Status'. Results (Table/Figure 1) indicate that $20.80 \%$ agreed $65.60 \%$ disagreed and $14 \%$ were not sure. The low percentage suggests that the English language is not considered as a symbol of status but rather it is considered as the language of education, learning and job, as discussed earlier. A significant fact about the behavior of human beings towards their social environment is a large part of its linguistic behavior (Michael Halliday, 1973). Thus, when applying MM to social status as something that influences marked choices, it can be extrapolated from the fact that $65 \%$ of respondents disagreed with the statement that social actors are more likely to make the unmarked choice to not code-switch to demonstrate their social status. 


\section{A profession as a social factor and its influence on English CM}

Results of social factor 'Profession' (Table/Figure 1) indicates that $56.80 \%$ agreed $37.60 \%$ disagreed and $6 \%$ were not sure whether 'Profession' influences their English codeswitching in the Pashto language or not. The percentage of 'agree' is fairly high which indicates that English CM is associated with the job. As discussed earlier (Table/Figure 1), it has been conferred that learning the English language is obligatory for getting white-collar jobs in multilingual companies, renowned NGOs, and in private schools and colleges. CM is the demand of certain jobs and it is used as a communicative strategy. Therefore, when considering the profession variable in the light of MM, it can be seen that there is an unmarked choice to code-switch in social situations that have a professional context. The normative model calls for code-switching in such a situation, which can be seen from the fact that $56 \%$ of respondents agreed with the statement.

\section{To impress upon others as a social factor and its influence on English CM}

Table/Figure (1) shows that $23.20 \%$ agreed $67.80 \%$ disagreed and $10 \%$ were marked as not sure. Linguistic behavior very often carries social meanings in it. It is used as a tool and instrument for getting a job, social status, and is sometimes used to impress others. Results show that $23.3 \%$ of English CM in the Pashto language occurs to impress others. The possible reason for this type of $\mathrm{CM}$ is that it helps the speaker to be called educated and get due respect in a certain group. This shows the greater solidarity of the Pashto speakers with their community and the use of the Pashto language as a social marker. Highlighting an interesting characteristic of the Pashtoon community, it can be seen from the high percentage of people who disagreed with the statement that they consider the normative model in general social situations to not call for code-switching and that many of them will not code-switch to change the RO to impress their status upon the other party in the social interaction.

\section{Social distance as a social factor and its influence on English CM}

It has been indicated that (Table/Figure 1) $22.40 \%$ agreed $63.20 \%$ disagreed and $14 \%$ were not sure. Sometimes language is used to alienate a particular group or an individual from conversation or to isolate oneself from others who do not know the language. It is also used to show solidarity with a certain group. The low percentage (20.40) shows that the influence of social distance on English CM is very low, which suggests that Pashto speakers do not appreciate the use of the English language to alienate a person who does not know English. In sociolinguistics, such an approach towards regional language is regarded as a positive approach and it helps in language maintenance (Peter Trudgill, 1992). Thus, from this it can be determined that for the Pashtoon community, the normative model in MM does not involve social distancing, so they will not make the marked choice to code-switch and alienate the other party in social interaction.

\section{Prestige as a social factor and its influence on English CM}

Results (Table/Figure 1) show that $54.40 \%$ agreed $32.20 \%$ disagreed and $13 \%$ were marked as not sure. In the results, the bar chart shows that $54.40 \%$ of the English CM is influenced by prestige as a social factor. This shows the attitude of the educated speech community that they consider English as a prestigious language. So far keeping in view the results, it has been observed that the Pashto language is used as a marker of identity and solidarity. These results suggest that the educated people are aware of the role of English as a global and instrumental language. English is used to identify oneself with the educated and learned class as it is the official language of the province and the medium of instruction in private schools and colleges.

This is an interesting finding since the dimension of prestige is close to that of status. While a large percentage would not make the marked choice to code-switch to demonstrate status, they would do so to demonstrate prestige. However, since in the Pashtoon community, education is closely linked to both status and prestige, as discussed earlier, the marked choice to depict prestige through code-switching stems from that particular factor.

\section{Confidence as a social factor and its influence on English CM}

Through results, (Table/Figure 1) it is shown that $56.00 \%$ agreed $36.00 \%$ disagreed and $8 \%$ were not sure. The use of English codeswitching in Pashto gave a feeling of satisfaction, self-encouragement, and ease; while also demonstrating the level of education. The use of English CM is a sign of overt prestige as the term introduced by William Labov (1966). This is another example of how education plays a large role in unmarked and marked choices in social interaction. From the result to this particular question, it can be seen that social actors will gladly overturn the existing RO in a social situation and code-switch to English to put themselves at ease in the interaction.

\section{Topic as a social factor and its influence on English CM}

It has been indicated that (Table/Figure 1) $57.60 \%$ agreed $24.00 \%$ disagreed and $18 \%$ marked not sure. The CM by interlocutors is highly associated with different topics. When the topic is local the ratio of codeswitching is very low and only borrowed words are used. This approach to language use is different from Fishman's claim that there exists an association between language and domain and he was concerned to establish patterns of language at a general level. The pattern of codeswitching in KPK is taking place at insertion levels. Only different vocabulary is used for different topics, situations, and participants. In MM, it is apparent that this particular factor refers to the normative model itself. The topic of conversation directly impacts the normative model, thus any choices that social actors make depending on the topic 
will be unmarked ones. If the topic calls for code-switching, then, as can be seen by the large number of respondents who agreed with the statement, they will make the unmarked choice to code-switch.

\section{Interlocutor as a social factor and its influence on English CM}

Results of (Table/Figure 1) shows that $84.80 \%$ agreed $12.00 \%$ disagreed and 3\% marked not sure. As in Fishman's (1965) research on Domain analyses the three factors; setting, participant, and topic were the leading factors that influence code choice. The result tells more about how different social norms are observed in KPK society. Most of the $\mathrm{CM}$ is taking place when the interlocutors are educated. In KPK society, social norms are strictly observed and English $\mathrm{CM}$ with illiterate interlocutors is considered as showing off.

Thus, in terms of MM, much depends on the prestige and education of the addressee. If the addressee is uneducated, the normative model itself will not call for the use of code-switching, thus the addresser will not make the marked choice to code-switch in such a situation, as can be seen from the overwhelming majority of respondents who agreed with the statement.

\section{Style as a social factor and its influence on English CM}

Results (Table/Figure 1) shows in percentage that out of 125 informants $26.40 \%$ agreed $64.00 \%$ disagreed and $10 \%$ were not sure. One of the major foci of sociolinguistic is the study of language and its social meanings. According to Eckert (2001) when any such category which differentiates one group from another or an individual from another based on their dressing, pronunciation, language use, and non-verbal actions, constitutes styles. Then the language practices of codeswitching according to the definition also constitute different styles. The result shows that the use of English CM in Pashto is very little influenced by style. The reason behind this is that Pashto is the dominant language of social identity. It suggests that the use of English is only associated with education and career advancement opportunities. This attitude towards languages in sociolinguistics has important effects which involved in the act of identity (Trudgill 1992). From this, it can be seen that some social actors will make the marked choice to code-switch in a social setting to impress their style upon others. The social factor of style is very much a marked choice and it can be seen from the results to this question that many will not make the marked choice to code-switch to demonstrate their style.

\section{Appropriateness of a social factor and its influence on English CM}

After data analysis, it is shown (Table/Figure 1) that in the percentage out of 125 informants $60.80 \%$ are agreed $22.40 \%$ disagreed and $17 \%$ are not sure. Appropriateness means when no alternate exists for a word in another language then appropriateness is taking place. One reason why Pashto speakers are prone to appropriateness is the vocabulary of the English language. English as a global language encompasses nearly all dimensions and it is very heavily featured in the native tongue of Pakistan.

When considering this social factor in light of MM, it is apparent that making a marked choice depends heavily on the normative model of social interaction. Over $60 \%$ of respondents claimed that they would not make a marked choice to code-switch if the RO of the interaction did not allow for it.

\section{Identity as a social factor and its influence on English CM}

The results (Table/Figure 1) show that out of 25 informants $22.40 \%$ agreed $64.80 \%$ disagreed and $13 \%$ were not sure. Language mixing, as we can call this rapid switching, also has the effect as the British sociolinguist Le page has pointed out, of enabling a speaker to signal two identities at once (Trudgill, 1974).

Through data analysis, it is found that $22.40 \%$ of English CM occurs due to this reason. This percentage shows that English CM in the Pashto language is very little influenced by identity as a social factor. It shows the social as well linguistic behavior of the reported group. There English CM is more influenced by their economical and educational need. Most of the educated people use English CM mixing as spontaneous as they are speaking pure Pashto as can be seen in data analysis (Table/Figure 1). Codeswitching can be used as an identity marker but only for educated people. Returning to the theme of education, it can be seen that that social factor very heavily influences marked choices. However, many Pashtoons do not view speaking English by itself to be deeply entwined with their identity, so they would not make the marked choice to code-switch in a social interaction where the normative model suggests that the main language should be Pashto. However, when considering the reverse, in a social interaction where the unmarked choice is to speak in English, the Pashtoon may code-switch to Pashto to deliberately change the RO and draw attention to his national and cultural identity.

\section{CONCLUSION}

The present study demonstrated that CM is a crucial phenomenon among educated bilinguals of the Pashto speech community. It plays a significant role in governing the social interaction of the community. In this study, it has been found that English codeswitching is influenced by different social factors and 'education' was the key factor influencing English CM in the Pashto language. The social factors which are associated with a positive attitude towards language use e.g., context, topic, interlocutor, profession, and prestige of English language, etc. showed that English is highly associated with the instrumental end and white-collar jobs. On the other hand, the other factors e.g., style, social distance, 
social status, and identity were found with a very low percentage which suggests that the language attitude of the Pashto speech community towards the Pashto language. It was found that the Pashto language is the dominant language of the community and the Pashto speakers use the Pashto language as a marker of identity. Codeswitching is not just the mixing of two languages but it talks about the language attitude of people towards the Pashto language. In terms of sociopragmatics, the role of codeswitching is significant; the study has demonstrated that codeswitching is a widely observed phenomenon in the educated people of KPK. It embodies different social functions.

The study extends empirical support to the typological approach to codeswitching of Pieter Muysken (2000). This study contributes to the ever-growing field of research on codeswitching to show the language attitude of the Pashto speech community. It has been found that codeswitching is used as a communicative strategy in a particular social context. This research tries to attract the interest of sociolinguists, anthropologists, and linguists as well as those involved in bilingual education or teaching English to Pashto-speaking students. The study creates awareness regarding English codeswitching in the Pashto language and had found the dominant factors that are responsible for this tendency as compared to the other social factors involved. These findings are useful to the language ideologies of the society at large.

\section{LIMITATION AND STUDY FORWARD}

This study is limited only to the Pashto speech community of Khyber Pakhtunkhwa, Pakistan. The present study is merely concerned with the influence of the social factors on English CM in the Pashto speech community. The study has included some of the social factors taken from the previous studies, but gender, social class, and age were not included as social factors. In future work, a researcher can work on social factors like social class, age, and gender and determine their influence on language on choice. Similarly, while an attempt was made to relate MM to the social factors researched, to some effect, deeper and more qualitative research is required to unearth the motivations of the Pashtoon community in making marked and unmarked choices to code-switch.

\section{ACKNOWLEDGEMENT}

The research work is developed with the collaboration of different scholars from different universities. All these scholars have collaborated voluntarily.

\section{AUTHORS CONTRIBUTION}

The leading author has floated the idea among these researchers and he developed the topic and introduction to the research. The second researcher has worked on the literature review section. The third has worked on the methodology and he developed the questionnaires for data collection. The fourth researcher has worked on the findings and conclusion.

\section{REFERENCES}

1. Auer, P. (1984). Bilingual Conversation. Amsterdam: John Benjamins. https://doi.org/10.1075/pb.v.8

2. Auer, P. (1988). A Conversation analytic approach to Code-switching and transfer. InHeller, M. (Ed), CodeSwitching: Anthropological and sociolinguistic perspectives (pp. 187-213). Berlin: Moulton de Gruyter.

3. Aure, P. (1998). Code-switching in conversation: Language, interaction, and identity. London: Routledge.

4. Auer, P. (1995). The pragmatics of code-switching: A sequential approach. In Milroy and Muysken, PP. 15-135. https://doi.org/10.1017/CBO9780511620867.006

5. Azuma, S. (1997). Lexical categories and code-switching: a study of Japanese/English code-switching in Japan. The Journal of the Association of Teachers of Japanese, 31(2), 1-24. https://doi.org/10.2307/489656

6. Azuma, S. (1993). The frame-content hypothesis in speech production: evidence from intra-sentential codeswitching. Linguistics, 31,107-194. https://doi.org/10.1515/ling.1993.31.6.1071

7. Backus, A. (1998). Two in One. Bilingual Speech of Turkish Immigrants in the Netherlands. Tiburg: Tiburg University Press.

8. Blom, J. P. and Gumperz, J. J. (1972). Social meaning in linguistic structures: Code-switching in Norway. New York: Holt, Rinehart, and Winston.

9. Blom, J. P., \& Gumperz, J. J. (2000). Social meaning in linguistic structure: Code-switching in Norway. The bilingualism reader, 111-136.

10. Blommaert, J. (1994). Code-switching and the exclusivity of social identities: Some data from Campus Kiswahili. Journal of Multilingual and Multicultural Development,13, 57-70. https://doi.org/10.1080/01434632.1992.9994483

11. Bucholtz, Marry, and Kira Hall. (2005). Identity and Interaction: A Sociocultural Linguistic Approach: Discourse Studies, 7, 4-5. https://doi.org/10.1177/1461445605054407

12. Chomsky, N. (1957). Aspects of the theory of syntax. Cambridge MIT Press.

13. Ervin-Tripp, S.M. (1964). An Analysis of the interaction of language, topic, and listener. American Anthropologist, 66, 86-102. https://doi.org/10.1525/aa.1964.66.suppl 3.02a00050

14. Ferguson, C.A. (1959) Diglossia. WORD, 15(2), 325-340. https://doi.org/10.1080/00437956.1959.11659702

15. Fishman, J. A. (1972). The sociology of language Rowley, Ma: Newbury House.

16. Fishman, J. A. (1965). Who speaks what language to whom and when? La Linguistique, 2, 67-88. 
17. Fishman, J. (1972). Domains and the relationship between micro and macrosociolinguistics. Directions in Sociolinguistics: The ethnography of communication. J.J. a. H. Gumperz, D. New York and Oxford, Basil Blackwell, pp. 435-453.

18. Khan, A. A. Anees, M. Rahman, G. (2020). The Patterns of Code-Switching in Pashto- English Bilingual Data. Global Social Science Review, V(I), 123 - 133. https://doi.org/10.31703/gssr.2020(V-I).13

19. Khan, A.A. Bukhari, H.N. \& Khalid, A. (2018). Pashto-English Bilingual data: Testing the Diagnostic Features for the Patterns of Codeswitching. Kashmir Journal of Language and Research, 21(1), 39-59

20. Khan, A. A. Khalid, A. (2018).Pashto-English Code-switching: Testing the Morphosyntactic Constraints of the MLF Model. Lingua-Elsevier, 201, 78-91. https://doi.org/10.1016/j.lingua.2017.09.002

21. Khan, A.A \& Bukhari, H.N. (2015). Pashto-English Code-switching: A Device for Indigenization and the use of Loanwords. Kashmir Journal of Language and Research, 18(3), 128-142.

22. Khan, A. A. \& P. Muysken. (2014) Strategies for incorporating nouns and verbs in codeswitching: the case of Pashto-English bilingual speech. Lapudum, 18, 97-137. https://doi.org/10.4000/lapurdum.2514

23. Khan, A.A. (2011). Social Factors and English Codeswitching in the Pashto Language. Germany: LapPublishing.

24. Gumperz, J. J. (1958). Dialect differences and social stratification in a North Indian Village. American anthropologist, 60(4), 668-682. https://doi.org/10.1525/aa.1958.60.4.02a00050

25. Gumperz, J. J. (1976). Language, communication, and public negotiation. In Anthropology and the public interest (pp. 273-292). Academic Press. https://doi.org/10.1016/B978-0-12-617650-6.50022-5

26. Gumperz, J. J. (1982). Discourse Strategies. Cambridge: Cambridge University Press. https://doi.org/10.1017/CBO9780511611834

27. Ho, J. W. Y. (2007). Code-mixing: Linguistic form and socio-cultural meaning. The International Journal of Language Society and Culture, 21(7), 1-8.

28. Hymes, D. (1972). On communicative competence. Sociolinguistics, 269-293.

29. Hymes, D. (1964). Introduction: Toward Ethnographies of Communication. American anthropologist, 66(6_PART2), 1-34. https://doi.org/10.1525/aa.1964.66.suppl_3.02a00010

30. Joshi. A. (1985). Processing sentences with intra-sentential code-switching ; in David Dowty. Lauri Karttunen and Arnold Zwicky (eds.) National LanguageParsing. New York: Academic press. pp. 190-205.

31. Kamwangamalu, N. M. (1989). Code-mixing and modernization. World Englishes, 8(3), $321-332$. https://doi.org/10.1111/j.1467-971X.1989.tb00672.x

32. Karchu. Y. (1989) Codeswitching, Style Repertoire and language Variation: English in Hindu Poetic Creativity. World Englishes, 8(3). https://doi.org/10.1111/j.1467-971X.1989.tb00671.x

33. Labov, W. (1966). Social stratification of English in New York City. Washington, DC. Center for Applied Linguistics.

34. Milroy, Lesly and Muysken, Pieter (eds.), (1995). One speaker, two languages, cross-disciplinary perspectives on code-switching. Cambridge University Press. https://doi.org/10.1017/CBO9780511620867

35. Muysken, P. (2000). Bilingual speech: A typology of Codeswitching.Cambridge University Press.

36. Myer-Scotton, C. (1992a). Constructing the frame in intrasentential code-switching. Multilingua, 11, 101-27. https://doi.org/10.1515/mult.1992.11.1.101

37. Myers-Scotton, C. (1993a). Duelling Languages: Grammatical structure in Code-switching. New York: Oxford University Press.

38. Myers-Scotton, C. (1993b) Social motivation for code-switching: Evidence from Africa. Oxford University Press.

39. Myers, C. L. (1998). A theoretical introduction to the markedness model. Codes and consequences: Choosing linguistic varieties, 18 .

40. Myers-Scotton, C (1998) Codes and Consequences: Choosing Linguistic Varieties. Oxford University Press US.

41. Myers-Scotton, C. and Bolonyai, A. (2001). Calculating speakers: Code-switching in a rational choice model. Language in society, 30, 1259-1271. https://doi.org/10.1017/S0047404501001014

42. Romaine, S. (1989). Bilingualism, Oxford: Blackwell.

43. Sapir, E. (1929). The Status of Linguistic as a Science. Language, 5(4), $207-214$. https://doi.org/10.2307/409588

44. Trudgill, P. (1992). Ausbau sociolinguistics and the perception of language status in contemporary Europe. International Journal of Applied Linguistics,2(2), 167-177. https://doi.org/10.1111/j.14734192.1992.tb00031.x

45. Trudgill, P., \& Trudgill, S. (1974). The social differentiation of English in Norwich (Vol. 13). CUP Archive. 